\title{
Performance of the LHC Final Prototype and First Pre-Series Superconducting Dipole Magnets
}

\author{
L. Bottura, G. D’Angelo, M. Gateau, P. Legrand, M. Modena, K. Naoui, D. Perini, P. Pugnat, S. Sanfilippo, F. Savary, \\ W. Scandale, A. Siemko, P. Sievers, G. Spigo, J. Vlogaert, and C. Wyss
}

\begin{abstract}
Within the LHC cryo-dipole program, six full-scale superconducting prototypes of final design were built in collaboration between Industry and CERN, followed by launching the manufacture of pre-series magnets. Five prototypes and the first of the pre-series magnets were tested at CERN. This paper reviews the main features and the performance of the cryo-dipoles tested at $4.2 \mathrm{~K}$ and $1.8 \mathrm{~K}$. The results of the quench training, conductor performance, magnet protection, sensitivity to ramp rate and field characteristics are presented and discussed in terms of the design parameters.
\end{abstract}

Index Terms-Field quality, LHC-main dipoles, quench, superconducting magnet, training.

\section{INTRODUCTION}

$\mathbf{T}$ HE LARGE Hadron Collider (LHC), now under construction at CERN, will provide proton-proton collision with a center-of-mass energy of $14 \mathrm{TeV}$ and an unprecedented luminosity of $10^{34} \mathrm{~cm}^{-2} \mathrm{~s}^{-1}$ [1]. To reach $7 \mathrm{TeV}$ per beam in the existing LEP tunnel presents some considerable technological challenges. The small tunnel cross-section as well as the need for cost reduction imposes a two-in-one magnet design for the main dipoles and quadrupoles. The $8.33 \mathrm{~T}$ operating field of main dipoles can only be obtained at an acceptable cost by cooling the magnets to $1.9 \mathrm{~K}$, below the lambda point of helium. This presents serious challenges to both the magnet designers and cryogenics engineers.

The experimental program on the LHC 10-m long, two-in-one, main dipoles started on the turn of 1989-1990. Since then, seven magnets of the first generation and five of the second generation have been built in industry and tested at CERN. The design and main test results of these magnets were described in several earlier publications [2]-[4].

In summer 1998, CERN launched in industry the fabrication of six full-scale dipole prototype collared coils of the third generation, i.e., with final design. These collared coils were subsequently assembled into cryo-dipoles at the CERN Magnet Assembly Facility (MAF).

In November 1999, CERN placed, with three European firms, a first order for three times thirty pre-series dipole cold masses. The first six pre-series cold masses (two per company) have been assembled like the prototypes at the MAF starting from collared coils produced in industry.

Manuscript received September 24, 2001.

The authors are with the European Laboratory for Nuclear Research, CERN, Geneva 23, CH-1211, Switzerland (e-mail: Pierre.Pugnat@cern.ch).

Publisher Item Identifier S 1051-8223(02)03461-9.
In this paper, the main test results of magnet prototypes of the last generation and first pre-series tested to date at the CERN Superconducting Magnet Test Plant (SMTP) will be reviewed. The results of quench training, conductor performance, magnet protection, sensitivity to ramp rate and field quality will be discussed in terms of the design parameters and the aims of the full-scale LHC dipole program.

\section{MAGNet DESIGN AND FABRICATION VARIANTS}

The design of the third and final generation of the LHC fullscale superconducting dipole prototypes has been described in details in earlier publications [5]-[7]. The construction of these magnets is the result of close collaboration between CERN and European Industry. Only the main design features and fabrication variants will be recalled here in view of the discussion of the test results.

\section{A. Main Design Features}

The third generation LHC-dipole coils are wound with two different, 15.1-mm wide, graded NbTi Rutherford cables. The cable for the inner layer consists of 28 strands of $1.065-\mathrm{mm}$ diameter, while that for the outer layer consists of 36 strands of $0.825-\mathrm{mm}$ diameter. As compared to the "5-block" coil of the second generation, in the third generation dipole coil the conductors of each quadrant are distributed in six blocks. The cable insulation is all polyimide and composed typically of two layers of $25-\mu \mathrm{m}$-thick tapes each overlapped by $50 \%$, and a third $70-\mu \mathrm{m}$-thick adhesive coated layer, spaced by $2 \mathrm{~mm}$ to provide channels for helium penetration into the coils.

\section{B. Manufacturing Features and Assembly Variants}

All two-in-one LHC-dipole magnets have a single race track type collar, embracing the coils of the two dipolechannels. Before the collaring process the thickness of the correcting shims is calculated on the basis of the required pre-stress, the actual size of the coils and the Young's modulus measurements. The target value of the residual pre-stress when cold is 25 to $35 \mathrm{MPa}$, on both the inner and the outer layer. The main manufacturing variants, specific for each company or introduced for evaluation in view of the series production are listed in Table I.

\section{Power Tests And Quench Performance}

For the cold tests, fully equipped 15 -m-long dipole units were installed on the newly constructed test stations at CERN. For testing, the beam screens are not installed in the magnet apertures. This permits insertion of the so-called anticryostats that 
TABLE I

Main Design and Assembly Variants of Full SCALE LHC-Dipoles

\begin{tabular}{|c|c|c|c|c|c|}
\hline & $\begin{array}{l}\text { Magnet } \\
\text { Name }\end{array}$ & $\begin{array}{c}\text { Coil Pre- } \\
\text { stress at } \\
293 \mathrm{~K}\end{array}$ & $\begin{array}{l}\text { Collar } \\
\text { Material }\end{array}$ & $\begin{array}{c}\text { Collaring } \\
\text { Procedures }\end{array}$ & $\begin{array}{l}\text { Collar } \\
\text { Packs }\end{array}$ \\
\hline \multirow{6}{*}{ 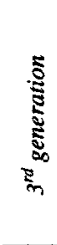 } & MBP2N1 & $40 / 40$ & Al & [Expandabl & 32 pairs \\
\hline & MBP2N2 & $72 / 85^{\mathrm{a}}$ & aus. steel & $\begin{array}{l}\text { e } \\
\text { |Mandrel }\end{array}$ & 32 pairs \\
\hline & MBP2O1 & $62 / 62^{a}$ & aus. steel & & 1 pair \\
\hline & $\mathrm{MBP} 2 \mathrm{O} 2$ & $54 / 63^{2}$ & aus. steel & |Mandrel & 1 pair \\
\hline & MBP2A1 & $50 / 40^{\mathrm{a}}$ & aus. steel & ÍRigid & 32 pairs \\
\hline & MBP2A2 & $56 / 60^{\mathrm{a}}$ & aus. steel & (Mandrel & 32 pairs \\
\hline \multirow{6}{*}{ 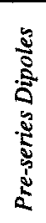 } & MBPSO01 & $90 / 90^{a, b}$ & aus. steel & All & 1 pair \\
\hline & MBPSO02 & $75 / 75^{a, b}$ & aus. steel & Collared & 1 pair \\
\hline & MBPSA01 & $80 / 80^{a, b}$ & aus. steel & on & 32 pairs \\
\hline & MBPSA02 & $70 / 75^{\mathrm{a}, \mathrm{b}}$ & aus. steel & the & 32 pairs \\
\hline & MBPSN01 & $70 / 70^{\mathrm{a}, \mathrm{b}}$ & aus. steel & cold & 32 pairs \\
\hline & MBPSN02 & $70 / 70^{a, b}$ & aus. steel & bores & 32 pairs \\
\hline
\end{tabular}

allow the measuring shafts for quench location and magnetic field quality measurements to be at room temperature [8].

\section{A. Quench Training}

The power tests of the dipoles are typically carried out in several runs separated by thermal cycles from $1.8 \mathrm{~K}$ to room temperature and back to $1.8 \mathrm{~K}$. For the standard training test, the quench current was reached with a nominal linear ramp rate of $10 \mathrm{~A} / \mathrm{s}$. Fig. 1 shows the quench performance recorded during the first runs for all prototypes of the last generation and first pre-series magnets tested to date. All of them reached the nominal field of $8.33 \mathrm{~T}$. Regarding the first quench level, the number of training quenches needed to exceed the nominal field and the memory effect after the thermal cycle, the first pre-series dipole magnets have shown on average better quench performance than the third generation prototypes ( $c f$. Table II). Comparing further the prototypes and the pre-series magnets, it follows that the performance enhancement depends on the collared coil manufacturer. So far, independently of the coil structural design, the general training performance is still influenced by the particular assembly details chosen by industry but this is less pronounced than in the prototypes. The same conclusion applies to the space and time distribution of the so-called spikes [9], the quench precursors resulting from conductor micromotions.

As noted in the study of the first prototypes of the third generation [4], an optimized design and manufacture of the coil ends where most of the training quenches occurred is of crucial importance. This matter is still receiving full attention and the improved training behavior shown in Fig. 1 for the last prototype and first pre-series dipoles may be explained by the positive corrections taken in the course of the prototype work (appropriate pre-stress, end-spacer shape and new, identical collaring procedures in all companies). The instabilities of the training curves shown in Fig. 1 mostly for prototypes, are attributed to a detraining effect. This effect has a thermomechanical origin induced by the coexistence of a mechanically weak region and

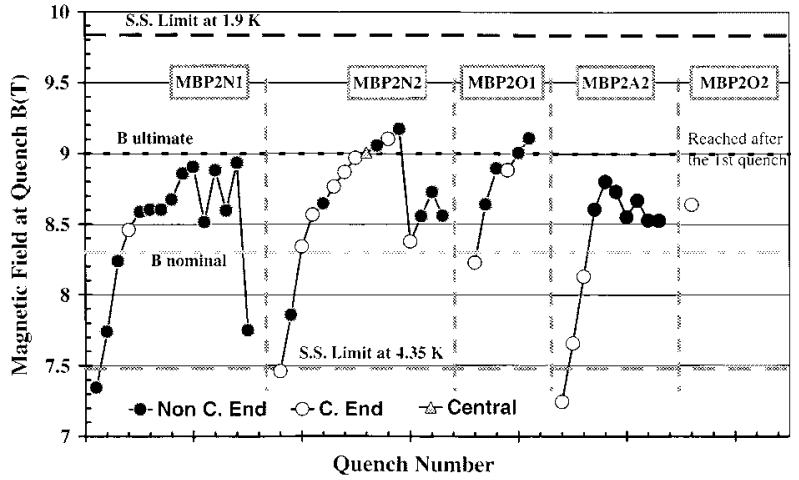

(a)

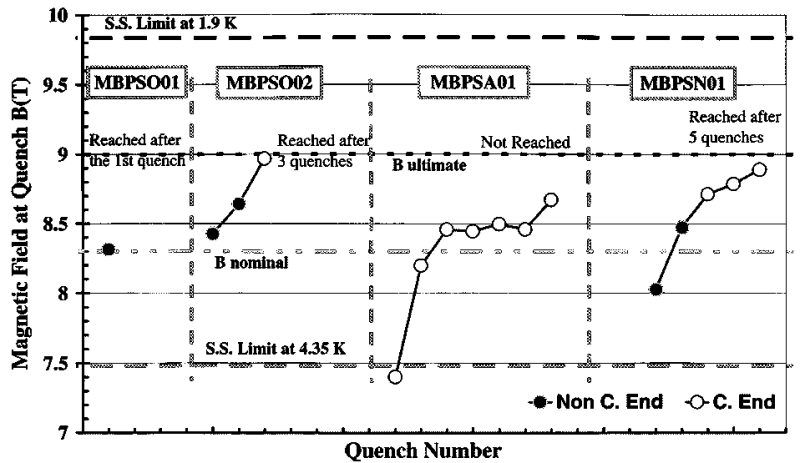

(b)

Fig. 1. Training curves recorded during the first runs for all third generation prototype (a) and pre-series (b) dipoles tested to date. Spot shapes denote the quench positions.

the temperature rise provoked by the energy deposited during the previous quench. The coil ends of the first pre-series magnets seem to exhibit less pronounced sensitivity to the detraining effect. This point can be correlated to the on-average better training performance of pre-series magnets with respect to prototypes as well as to the better memory effect after thermal cycle ( $c f$. Table II). The mechanical weakness of the magnet ends reflected in the location of training quenches, summarized in Fig. 1, depends on the cold mass manufacturer.

\section{B. Magnet Protection}

All LHC main dipole and quadrupole cryo-magnets are protected against quench induced damage by means of quench heaters activated by the quench detection electronics. For certain types of tests, like quench training, an external dump resistor is used to extract between $10 \%$ and $20 \%$ of the total stored energy inside the magnets. To ensure safe operation of these magnets when connected in series to constitute the LHC storage ring, provoked quenches without energy extraction at various fields have been performed and analyzed. The aim of these tests was to investigate the efficiency of quench heaters as well as to validate the final version of the protection scheme for the LHC dipoles [10]. The tests demonstrated that the proposed quench heater scheme is fully redundant, and that neither the highest hot-spot temperatures reached during quenches at high currents nor the resulting voltages to ground exceed the design values [10], [11]. 
TABLE II

Summary of TRAINING Quench PERFormance

\begin{tabular}{|c|c|c|c|c|c|}
\hline & $\begin{array}{l}\text { Magnet } \\
\text { Name }\end{array}$ & $\begin{array}{c}\text { First } \\
\text { quench } \\
{[\mathrm{T}]}\end{array}$ & $\begin{array}{l}\text { No of } \\
\text { q. to } \\
8.33 \mathrm{~T}\end{array}$ & $\begin{array}{l}\text { No of } \\
\text { q. to } \\
9 \mathrm{~T}\end{array}$ & $\begin{array}{l}1^{\text {st }} \mathbf{q} \cdot \text { after } \\
\text { th. cycle }[\mathrm{T}]\end{array}$ \\
\hline \multirow{5}{*}{ 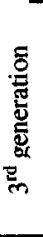 } & MBP2N1 & 7.35 & 3 & $>15$ & 8.39 \\
\hline & MBP2N2 & 7.46 & 2 & 8 & - \\
\hline & MBP2O1 & 8.23 & 1 & 5 & 8.76 \\
\hline & $\mathrm{MBP} 2 \mathrm{O} 2$ & 8.64 & 0 & 1 & 8.85 \\
\hline & $\mathrm{MBP} 2 \mathrm{~A} 2$ & 7.25 & 3 & $\begin{array}{c}\text { Not } \\
\text { reached }\end{array}$ & 7.98 \\
\hline \multirow{6}{*}{ 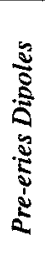 } & MBPSO01 & 8.31 & 1 & $1^{\mathrm{b}}$ & No quench up to 9T \\
\hline & MBPSO02 & 8.43 & 0 & 3 & No quench up to $9 \mathrm{~T}$ \\
\hline & MBPSA01 & 7.4 & 2 & $\begin{array}{l}\text { Not } \\
\text { reached }\end{array}$ & 8.38 \\
\hline & MBPSN01 & 8.03 & 1 & 5 & 8.86 \\
\hline & MBPSN02 &.$^{\mathrm{a}}$ &.$^{a}$ &.$^{a}$ & $-{ }^{a}$ \\
\hline & MBPSA02 & $\mathrm{A}^{\mathrm{a}}$ & $\AA^{\mathrm{a}}$ & $\AA^{\mathrm{a}}$ & $\AA^{a}$ \\
\hline
\end{tabular}

${ }^{\mathrm{a}}$ Magnet not yet tested.

${ }^{b}$ Detraining and re-training after the provoked quench at the nominal field; this type of tests is foreseen to check the quench heaters efficiency.

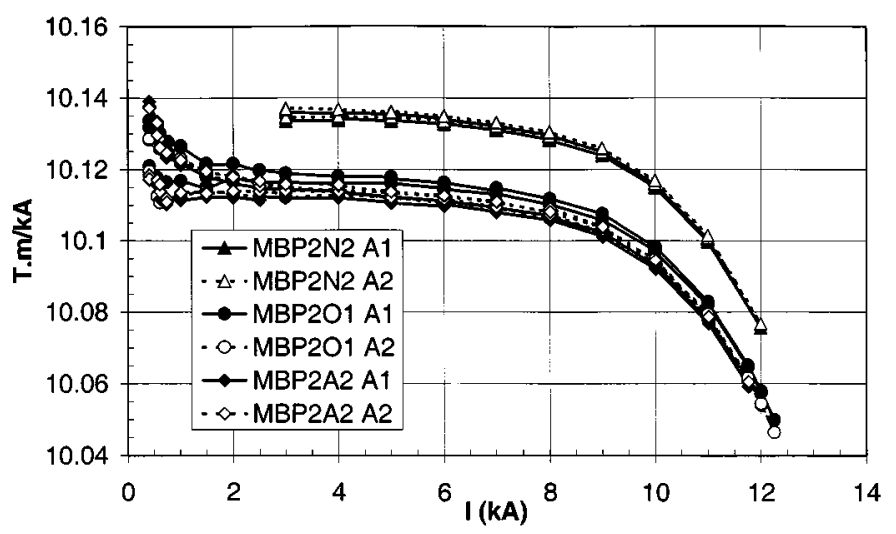

(a)

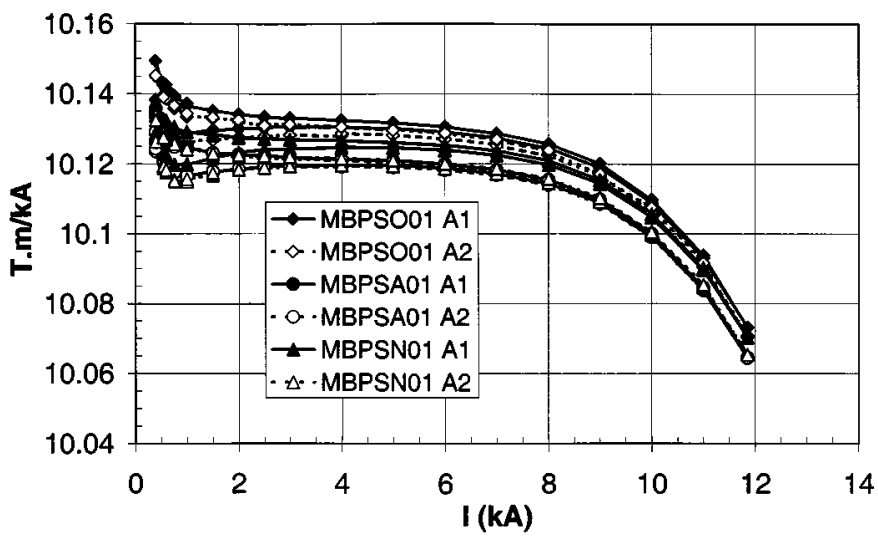

(b)

Fig. 2. Integrated transfer function of some prototypes (a) and pre-series dipoles (b).

\section{Quench Sensitivity to the Ramp Rate}

The sensitivity of the quench performance to ramp rate of the third generation prototypes and first pre-series dipoles is in general very low and not much different from magnet to magnet. Results show significant improvements in this respect as compared to the second generation of prototype magnets, thanks to the strand coating $\left(\mathrm{SnAg}_{5 \%} \mathrm{wt}_{\mathrm{wt}}\right.$ ) and oxidation process developed at CERN for the third generation prototypes, pre-series, and series magnets [12]. The control of the contact resistances between strands of the cable is also confirmed by loss measurements, ramp rate effect on the field quality [13] and by the amplitude of the periodic field modulation measured inside apertures of the third generation prototypes and first pre-series dipoles [14].

\section{FIELD QUALITY}

The field quality of the 15-m-long dipoles prototypes and the first four pre-series was measured with a long rotating coil system [8]. Measurements were performed at several field levels, including injection $(0.54 \mathrm{~T})$ and nominal $(8.33 \mathrm{~T})$. In Fig. 2, the integrated dipole transfer function along the magnet length is given for three prototypes of the last generation and the three first pre-series magnets. For prototypes, the spread between the integrated transfer function can be correlated with the size of the shims. This is not the case for the pre-series dipoles. Concerning the current dependence, the transfer functions measured are compared to the calculated ones and discussed in a separate paper [15].

A summary of the measured field errors at injection and at nominal field is shown in Fig. 3 for the last prototypes and the first pre-series magnets. Normal and skew harmonic field components, $b_{n}$ and $a_{n}$, respectively, are normalized to the dipole field, scaled by a factor $10^{4}$ and expressed at a reference radius of $17 \mathrm{~mm}$. The harmonics plotted are averaged over the whole magnet length, including ends.

Detailed investigations of the geometrical error contribution and of the saturation effect on harmonics are given in [15]. The $b_{2}$ component is found to be significantly reduced for pre-series dipoles in comparison to the prototypes. This improvement of the field quality can be explained by the modification of the geometry of the insert.

The field components outside tolerances which should be mentioned are the normal sextupole $\left(b_{3}\right)$ and the normal decapole $\left(b_{5}\right)$ terms. The larger freedom inherent in the 6-block design with respect to the previous 5-block one, makes it possible to fine-tune the final geometry of pre-series dipoles to achieve optimal field quality for machine operation. The tuning process will principally focus on the $b_{3}$ and $b_{5}$ components and before the start of the series production, a correction of the coil design will be done through a small change of the copper wedges (up to $0.5 \mathrm{~mm}$ ), leaving the coil azimuthal length unchanged.

The persistent current contribution to $b_{3}$ and $b_{5}$ is essentially the same for prototypes and first pre-series magnets and no significant change can be observed for harmonics of higher order.

\section{CONCLUSION}

An extensive test and analysis program is being pursued for the LHC main dipole prototype and first pre-series magnets. To this point, all tested magnets passed the nominal field of $8.33 \mathrm{~T}$. Results show that the first pre-series dipole magnets display on average better quench performance than the prototypes. This includes better training behavior, better memory effect, and a coil structure less sensitive to detraining effect. Concerning the field 


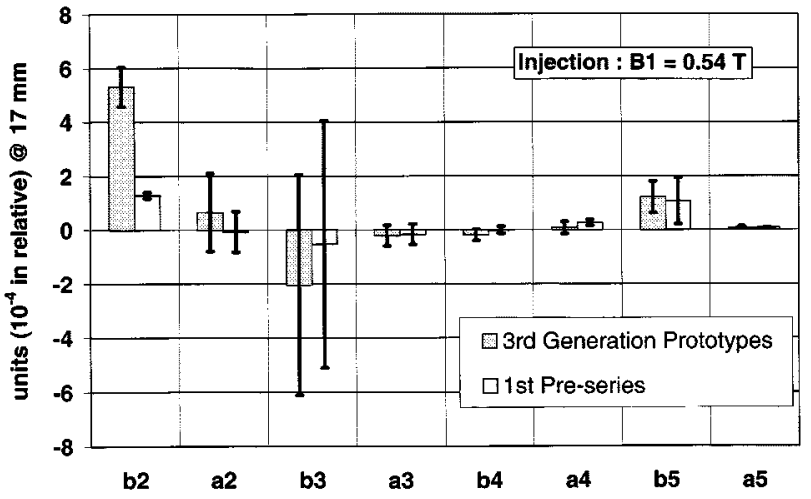

(a)

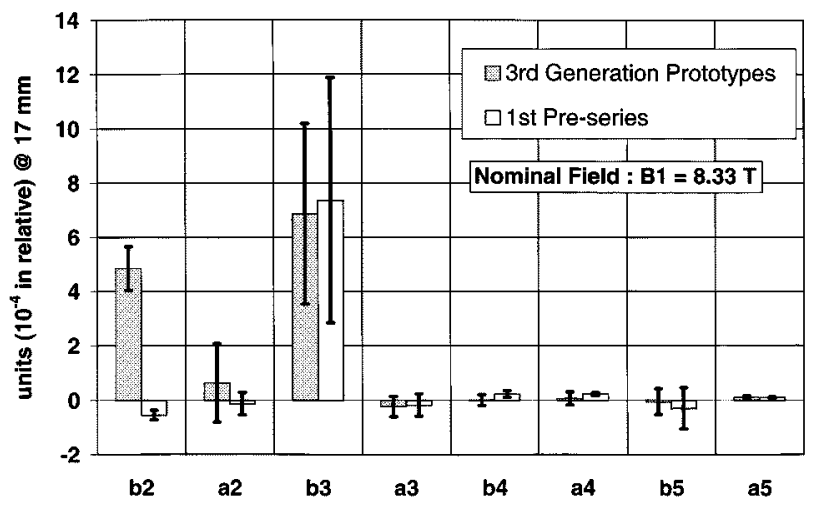

(b)

Fig. 3. Summary of harmonics measured at injection (a) and at the nominal field (b) in last prototypes and first pre-series dipoles. The harmonics reported are average values over the magnets of the same family. The bars represent the standard deviation around the average.

quality, the $b_{2}$ and $a_{2}$ harmonic components were significantly reduced for pre-series dipoles. However this improvement has not yet been achieved for the $b_{3}$ and $b_{5}$ components for which a fine-tuning of the coil structure is necessary and is now in progress.

As already reported for the prototypes of the third generation [4], the quench performance of the first pre-series dipoles still carries the signature of the manufacturers but in a less pronounced way. The results of the field quality seem also to be predominantly related to the particular assembly details.

In view of the LHC main dipole series production, significant efforts are now devoted to standardise and homogenise manufacturing processes. All these operations are controlled by strict assembly and quality assurance procedures and finally by thorough cold testing prior to installation.

\section{ACKNOWLEDGMENT}

The authors wish to thank L. Evans and Ph. Lebrun for their constant support and are very grateful to the teams in Industry and at CERN involved in the construction and testing of the LHC main cryo-dipole magnets.

\section{REFERENCES}

[1] The LHC Study Group, "The large hadron collider conceptual design," in CERN/AC/95-05(LHC): CERN, Oct. 20, 1995.

[2] J. Billan et al., "Manufacturing features and performances of long models and first prototype for the LHC project," in Proc. 6th Europ. Part. Acc. Conf., Stockholm, 1998, pp. 2041-2043.

[3] J. Billan et al., "Test results on the long models and full scale prototype of the second generation LHC arc dipoles," IEEE Trans. Appl. Supersonduct., vol. 9, pp. 1039-1044, 1999.

[4] L. Bottura, P. Pugnat, A. Siemko, J. Vlogaert, and C. Wyss, "Performance of the LHC final design, full-scale superconducting dipole prototypes," IEEE Trans. Appl. Superconduct., vol. 11, pp. 1554-1557, Mar. 2001.

[5] C. Wyss, "LHC arc dipole status report," in Proc. 1999 Part. Acc. Conf., New York, 1999, pp. 149-153.

[6] K. Artoos et al., "Design, manufacturing status, first results of the LHC main dipole final prototypes and steps toward series manufacture," IEEE Trans. Appl. Superconduct., vol. 10, pp. 98-102, Mar. 2000.

[7] S. Russenschuck, "Comparative study of different coils for the LHC main dipoles," in Roxie: Routine for the Optimization of Magnet X-Sections, Inverse Field Calculation and Coil End Design, S. Russenschuck, Ed: CERN 99-01, Apr. 12, 1999.

[8] J. Billan et al., "Twin rotating coils for cold magnetic measurements of 15-m long LHC dipoles," IEEE Trans. Appl. Superconduct., vol. 10, pp. 1422-1426, Mar. 2000.

[9] P. Pugnat, B. Khomenko, A. Rijllart, S. Sanfilippo, and A. Siemko, "Statistical diagnosis method of conductor motions in superconducting magnets to predict their quench performance," IEEE Trans. Appl. Superconduct., vol. 11, pp. 1705-1708, 2001.

[10] F. Rodriguez-Mateos, R. Schmidt, A. Siemko, and F. Sonnemann, "Quench process and protection of LHC dipole magnets," CERN, LHC Project Note 184, July 1,1999

[11] F. Rodriguez-Mateos, P. Pugnat, S. Sanfilippo, R. Schmidt, A. Siemko, and F. Sonnemann, "Quench heater experiments on the LHC main superconducting magnets," in Proc. 7th Europ. Part. Acc. Conf., Vienna, 2000, pp. 2154-2156.

[12] J. Adam, T. Boutboul, G. Cavallari, Z. Charifoulline, C.-H. Denarie, S. Le Naour, D. F. Leroy, L. R. Oberli, D. Richter, A. P. Verweij, and R. Wolf, "Status of the LHC superconducting cables mass production,", submitted for publication.

[13] A. Akhmetov et al., "Loss and dynamic magnetic field measurements in LHC dipoles,", submitted for publication.

[14] P. Pugnat, Th. Schreiner, and A. Siemko, "Investigation of the periodic magnetic field modulation in LHC superconducting dipoles,", submitted for publication.

[15] S. Sanfilippo et al., "Measurements and analysis of the field quality of the LHC superconducting dipoles,", submitted for publication. 